\title{
Do patient-reported outcome measures cover personal factors important to people with rheumatoid arthritis? A mixed methods design using the International Classification of Functioning, Disability and Health as frame of reference
}

Mona Dür ${ }^{1,2^{*}}$, Michaela Coenen ${ }^{3}$, Michaela Alexandra Stoffer ${ }^{1}$, Veronika Fialka-Moser ${ }^{4}$, Alexandra Kautzky-Willer ${ }^{5}$, Ingvild Kjeken ${ }^{6}$, Răzvan Gabriel Drăgoi ${ }^{7}$, Malin Mattsson ${ }^{8,9}$, Carina Boström ${ }^{10}$, Josef Smolen ${ }^{1}$ and Tanja Alexandra Stamm ${ }^{1,11^{*}}$

\begin{abstract}
Background: Personal factors (PFS) are internal factors that determine functioning and the individuals' experience of disability. Their coverage by patient-reported outcome measures (PROMs) has not been examined in rheumatoid arthritis (RA) so far. The aims of this study were to identify PFs important in the life stories of people with RA and to determine their coverage by PROMs used in RA.
\end{abstract}

Methods: The qualitative data of people with RA was explored to identify PFs. Additionally a systematic literature search was conducted to find PROMs used in RA. PROMs items were linked to the components, domains and categories of the International Classification of Functioning, Disability and Health (ICF) to determine the coverage of important PFs by PROMs.

Results: Twelve PFs were found to be important in the life stories of people with RA. The PFs coping and reflecting about one's life in an optimistic way were covered most frequently, each by 14 of the 42 explored PROMs, while job satisfaction was not covered at all. The London Coping with Rheumatoid Arthritis Questionnaire, General Self-Efficacy Scale, Arthritis Self-Efficacy Scale, Rheumatoid Arthritis Self-Efficacy Questionnaire and Revised Ways of Coping Inventory covered most PFs. Nineteen PROMs did not cover any of the PFs.

Conclusion: Several PFs were identified as important in the life stories of people with RA, but only 55\% of the PROMS covered some of these PFs. When evaluating PFs important to people with RA, health professionals should be alert on which PROMs can be used to assess which PFs.

Keywords: Qualitative research methods, Health promotion, Outcome research, Patient perspective, Rehabilitation

\footnotetext{
* Correspondence: mona.duer@fh-krems.ac.at; tanja.stamm@meduniwien.ac.at 'Deceased

'Medical University of Vienna, Department of Internal Medicine III, Division of Rheumatology, Währinger Gürtel 18-20, 1090 Vienna, Austria

Full list of author information is available at the end of the article
} 


\section{Background}

Rheumatoid arthritis (RA) is a chronic autoimmune disease, characterized by joint inflammation, pain, joint swelling, morning stiffness, and fatigue which may lead to loss of functioning in daily life [1]. The prevalence ranges from $0,5-2 \%$ and is $3-4$ times higher in women than in men [2]. However, the current understanding of the burden of the disease comprises not only clinical symptoms, but also other aspects that have an impact on living with RA, including environmental factors and personal factors, such as people's social support or self-efficacy [3-5].

The International Classification of Functioning, Disability and Health (ICF) [6] is a common conceptual framework used to understand, describe and measure the dimensions of human functioning, disability and health [7]. Within the ICF, an individual's functioning is conceptualized as result of the interplay between body functions and structures, activities and participation and contextual factors that include environmental and personal factors $(P F s)[6]$.

$P F s$ have played a tangential part in relation to ICFbased health outcome research. In the ICF, PFs are defined as internal factors that determine functioning and the individuals' experience of disability. PFs comprise "features of the individual" such as coping, social background and psychological factors impacting health outcomes [6]. However, even if a few researchers have explored PFs through consensus processes [8], systematic reviews [9] or qualitative interviews with patients [10], they are not yet classified according to the ICF "taxonomy" [6,7].

For example, the RA ICF core set was developed to provide a set of categories that best describes the problems of functioning of people with RA [11]. Within three validation studies based on qualitative data several $P F s$ were identified as meaningful which have not been covered by the ICF core sets [12-15]. Further, even though single PFs have been explored in people with RA [16,17], they have been left out in the examination of the coverage of the perspectives of patients with RA by patientreported outcome measures (PROMs), as it has been done in other chronic diseases [18-20]. Thus, it is unclear how PROMs cover PFs important to people with RA. Additionally, PFs and their meaning to people with RA may change over time and the course of disease $[21,22]$. Hence, they need to be explored within a longterm perspective over the life course.

Furthermore, the new and effective biologic therapies facilitate the inclusion of other important aspects such as PFs as targets of non-pharmacological treatment of people with RA $[6,23,24]$. For example, interventions targeting $P F s$, such as coping strategies or medication beliefs, could support individuals to achieve their fullest potential on functioning, to reduce the impact of RA
$[24,25]$, and to increase medication adherence [26]. To assess the need for or to evaluate non-pharmacological treatment in clinical practice or rehabilitation targeting $P F s$, health professionals and researchers should be alert on which PROMs cover which PFs.

The aims of this study were to identify PFs important in the life stories of people with RA and to determine their coverage by PROMs used in RA.

\section{Methods}

We used a mixed methods design consisting of a qualitative analysis, a systematic literature search and a linking process. The current project was part of a larger study $[27,28]$.

\section{Exploration of qualitative data to identify personal factors} important in the life stories of people with RA

Firstly, a secondary analysis of qualitative data of a previous study $[29,30]$ was conducted. In the respective study, patients from the rheumatologic outpatient clinic of the Medical University of Vienna, Austria, diagnosed with RA [31] were asked for participation. A small sample size of 15 participants with a diverse range was aimed to gather rich and meaningful data [32]. Recruitment used a maximum variation sampling strategy [33] in terms of sex, age, former professional status and disease duration. Inclusion criteria were "being early retired" at the time of the interviews, having past employment experience ( $\geq 20$ hours per week), no history of psychiatric and/or other neuro-motor disease and German as first language. Since we were interested in the identification of PFs which could be complex, such as coping or resilience, we decided to use people's life stories and to follow the biographical narrative interpretative method (BNIM) $[33,34]$. In accordance to the study aim the interviews' verbatim transcripts of the life stories were used to determine $P F s$ which were important over the life and disease course of people with RA. Therefore, each transcript was analyzed by two researchers independently (MD, MS, and TAS). In case of disagreement, each case was discussed in a research panel of three people who together made a final informed decision, whether or not a certain $P F$ was encompassed in the respective life story. PFs which were found among different life stories were identified based on the exploration of people's interpretation of their life's experience and their biography [34] and used for the exploration of their coverage by PROMs. A flow chart of the different steps of the BNIM is depicted in Figure 1. For detailed information we refer to further literature $[33,34]$.

\section{Systematic literature search to find PROMs used in RA}

Secondly, we conducted a systematic literature search in 2013 using PubMed, CINAHL and PsycInfo to find PROMs used in RA and to extract their items. The 


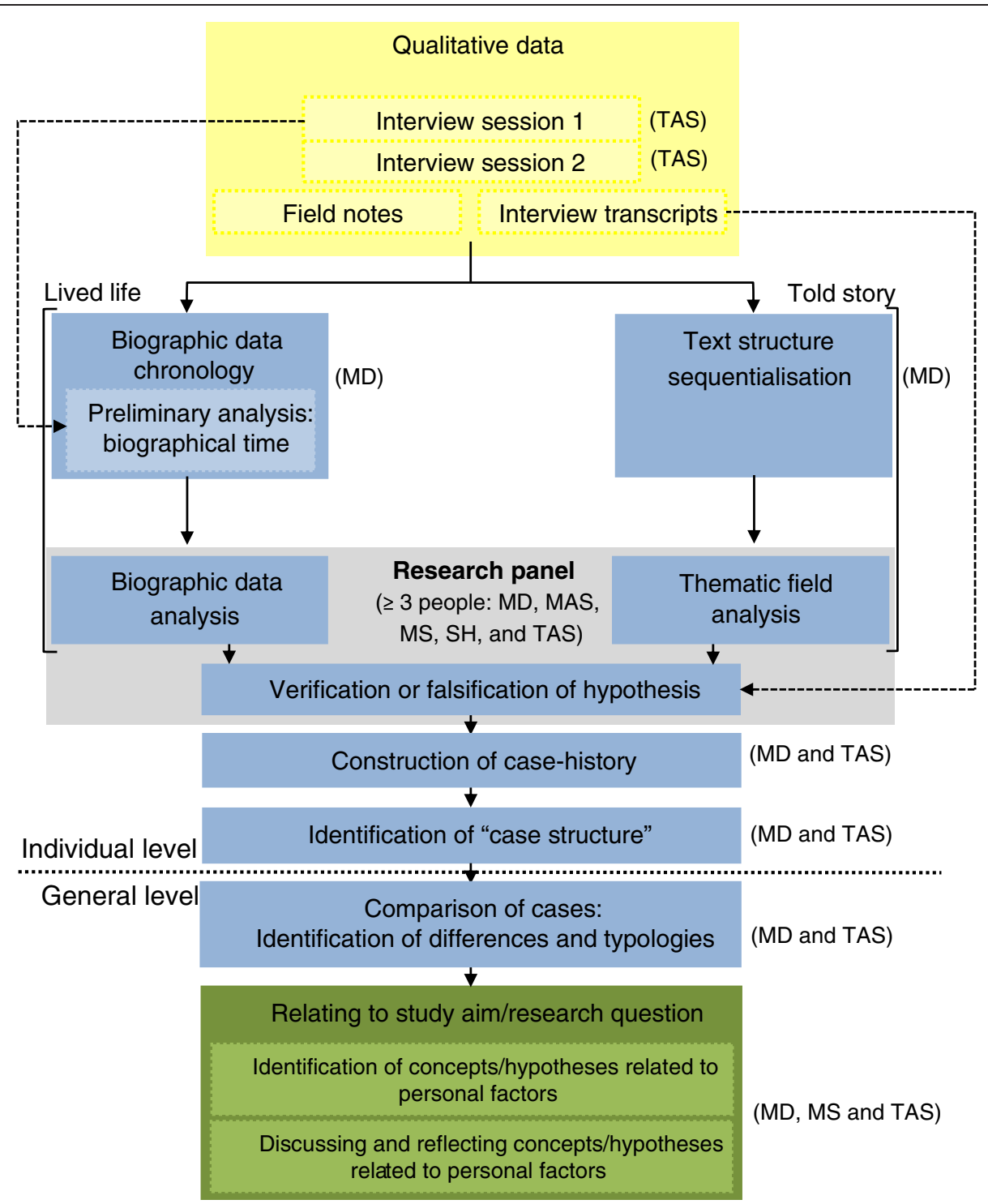

Figure 1 Flow diagram of the data collection and analysis following the BNIM. (Initials) $=$ researcher(s) who conducted the respective step of the BNIM.

following combination of keywords was used to search the articles: [(rheumatoid arthritis)] AND [(outcome) OR (assessment) OR (instrument) OR (measure) OR (questionnaire)] AND [(self-reported) OR (patient-reported) OR (patient perspective)]. For inclusion, articles had to be written in English and published in a peerreviewed journal and the description of the use or development of at least one PROM had to be contained in the title or the abstract. Candidate articles were independently reviewed by two researchers (MD and $A B$ ) using a data extraction form, to identify the descriptions of PROMs. A PROM was included when the following criteria were applied: assessing functioning and/or functional health and/ or those PFs which were identified in the qualitative analyses. PROMs items which were not provided within these articles were obtained from reference checking or on request from their authors. PROMs specifically designed for children or adolescents and single-VAS-assessments for disease activity of RA were excluded.

\section{Linking process to determine the coverage of important personal factors by PROMs}

Finally, we determined which $P F s$ were covered by which PROMs using the ICF [6] as reference. Items of the PROMs were linked to ICF categories by two researchers (MD and $\mathrm{MC}$ ). In case of disagreement an informed decision was made by one further researcher skilled and experienced in the ICF linking process (TAS). The linking process followed a standard procedure by the use of the current ICF-linking rules [35]. 
Concerning the complexity of certain items, we applied the ICF-linking rule referring to items encompassing different constructs, an example is shown in Figure 2. Articles providing ICF categories linked to the selected PROMs were used.

The linked ICF categories of each PROM were compared to the $P F s$ from the qualitative data by mapping them to each other. Finally, PROMs were explored in order to report how many PROMs were available to assess each PF and those PFs for which no PROM existed. An example is given in Figure 2.

\section{Ethical considerations}

Participants received information about study procedures and ethical considerations and gave written and oral informed consents. Confidentiality was guaranteed and names were changed in the given examples. The study was approved by the ethics committee of the Medical University of Vienna, Austria.

\section{Results}

Personal factors important in the life stories of people with RA

For the current study, we used the data of 15 people with RA, 11 women and 4 men with a median age of 54 years and disease duration of 11 years [29,30]. Demographic data is depicted in Table 1.

In the secondary analysis of the life stories of people with RA the following 12 PFs were identified as being important: Adaptation to changed living conditions; coping; eating habits and weight concerns; involvement into disease management; job satisfaction; meaningful activities for the individual and/or the societal context; own attitudes; reflecting about one's life in an optimistic way; resilience; self-efficacy; sense of coherence and social appreciation.

In the following section, we give two examples of important PFs: In the life story of Hans, a 58 years old varnisher, we identified adaptation to changed living conditions. Hans

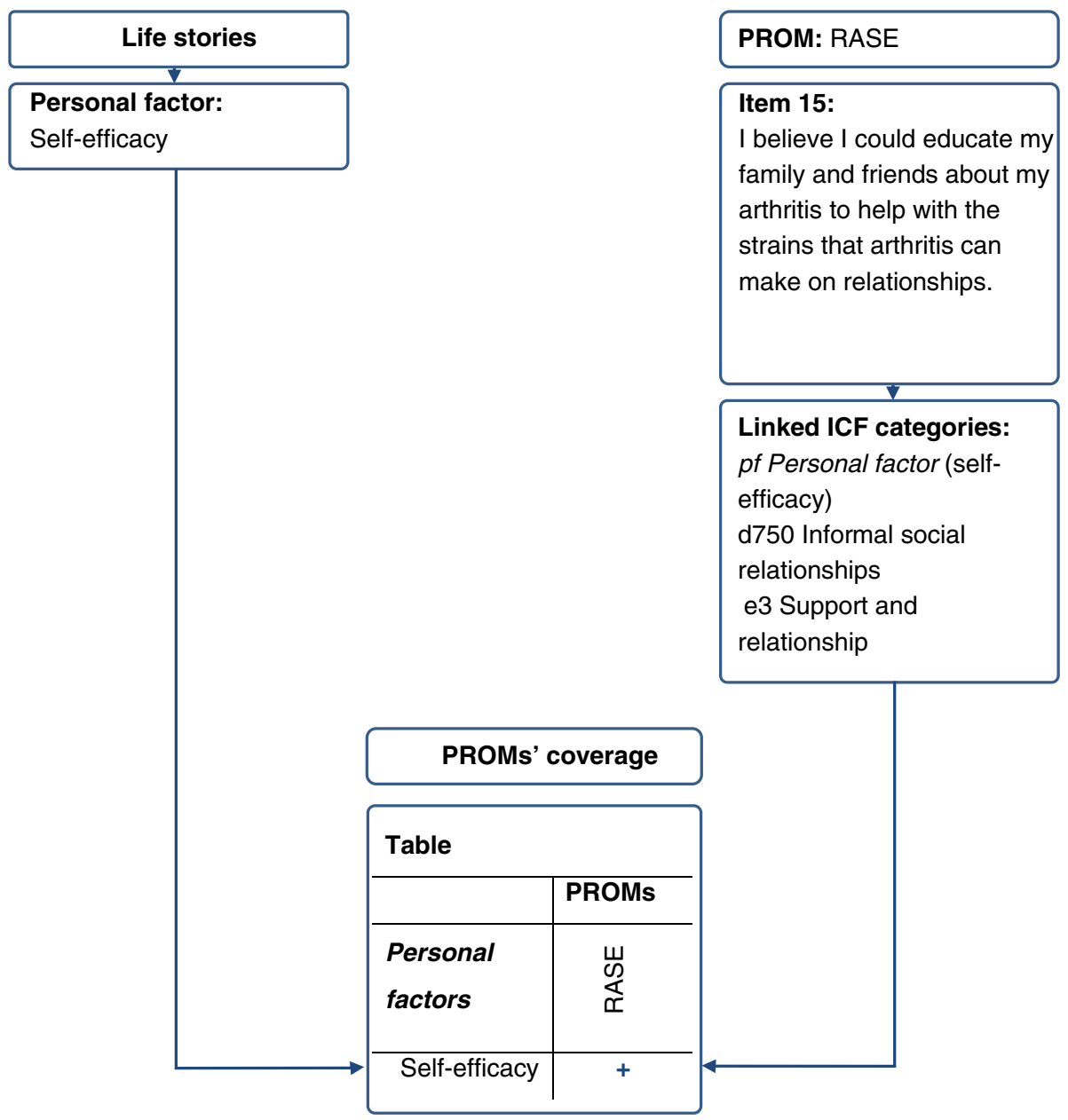

Figure 2 Example: Linking process to determine the coverage of important personal factors by patient-reported outcome measures. Comparison of one personal factor to one linked item of the Rheumatoid Self-efficacy Questionnaire; Abbreviations: ICF = International Classification of Functioning, Disability and Health, PROMs = Patient-reported outcome measures, RASE = Rheumatoid Self-efficacy Questionnaire. 
Table 1 Demographic data of the participants

\begin{tabular}{lll}
\hline & Women & Men \\
\hline$n(\%)$ Total & $11(73)$ & $4(27)$ \\
$n(\%)$ International Standard Classification & $6(55)$ & $3(75)$ \\
of Education (ISCED) level 3: completed & & \\
$\begin{array}{l}\text { vocational education or secondary education } \\
\text { premising the access to higher education }\end{array}$ & & \\
Median Age (interquartile range) & $52(43-61)$ & $56(42-58)$ \\
Median Disease duration (interquartile range) & $10(8-20)$ & $14(10-26)$ \\
\hline
\end{tabular}

did not get a job after he had left the previous one. Thus, his life story contained several descriptions on changes which were adaptations to living with RA:

"Depressing when you suddenly become useless at the age of 40, not knowing how life will go on and how to get oneself and one's family. So, my wife worked half time and I took care of the children, as far as that was possible”. (First interview, lines 51-53)

Another example is Maria, a 42 years old woman. She did not let the disease "rule" her life and supported others to care about their health and wellbeing. Finally, Maria became an "advocate" for people with RA. We identified self-efficacy and involvement into disease management when she told about her engagement in acquiring knowledge and skills.

"What I wanted to know was how to handle it [the disease]? So, I asked my physician [rheumatologist] to prepare me for the case that the worst happens and we talked it through. I have written down everything. In the case I found myself in troubles, I looked through my notes and could help myself”. (First interview, lines 537-546)

"My ambition spurred me on, not to accept everything related to the disease and to let it rule my life. I have bought medical books, attended specialist conferences [on rheumatic diseases], I went to libraries and studied [RA specific] drugs and their side effects. I started to understand the physician a little when he talked about the medication. I felt that I could have a determining influence on the decision which drug should be tried next". (First interview, lines 687-701) "I realized that meanwhile I was engaged in the management of my disease to the same extent as I was engaged in my job formerly". (First interview, lines 719-721)

Three PFs were found to be important in the life stories of women only. These were reflecting about one's life in an optimistic way, involvement into disease management and job satisfaction. While coping and meaningful activities for the individual and/or the social context was
Table 2 Frequency of personal factors per sex

\begin{tabular}{lllll}
\hline $\mathbf{R}$ & Personal factors & $\mathbf{n ( \% )}$ & $\mathbf{f ( \% )}$ & $\mathbf{m}(\%)$ \\
\hline $\mathbf{1}$ & Own attitudes & $13(87)$ & $11(100)$ & $2(50)$ \\
$\mathbf{2}$ & Adaptation to changed living conditions & $11(73)$ & $9(82)$ & $2(50)$ \\
$\mathbf{3}$ & Meaningful activities for the & $12(80)$ & $8(73)$ & $4(100)$ \\
& individual and/or the social context & & & \\
$\mathbf{4}$ & Eating habits and weight concerns & $10(67)$ & $8(73)$ & $2(50)$ \\
$\mathbf{5}$ & Coping & $9(60)$ & $5(45)$ & $4(100)$ \\
$\mathbf{6}$ & Reflecting about one's life in & $7(47)$ & $7(64)$ & 0 \\
& an optimistic way & & & \\
$\mathbf{6}$ & Involvement into disease management & $7(47)$ & $7(64)$ & 0 \\
$\mathbf{6}$ & Self-efficacy & $7(47)$ & $6(55)$ & $1(25)$ \\
$\mathbf{7}$ & Sense of Coherence & $6(40)$ & $4(36)$ & $2(50)$ \\
$\mathbf{8}$ & Job satisfaction & $5(33)$ & $5(45)$ & 0 \\
$\mathbf{9}$ & Social appreciation & $4(27)$ & $3(27)$ & $1(25)$ \\
$\mathbf{9}$ & Resilience & $4(27)$ & $2(18)$ & $2(50)$ \\
\hline
\end{tabular}

Abbr.: $\mathrm{R}=$ Rank, $\mathrm{n}=$ number $\mathrm{f}=$ female, $\mathrm{m}=$ male.

important in the life story of all men, the same was true for own attitudes in women. The frequency and percentage of identified PFs per sex are depicted in Table 2.

\section{PROMs used in RA}

The systematic literature search resulted in 1280 hits, of which 831 were excluded due to 107 duplicates and 724 irrelevant articles. Finally, 449 articles were used to identify the PROMs used in RA, as described in Figure 3.

In total forty-two PROMs met our inclusion criteria. They are listed and described in Table 3.

\section{PROMs coverage of important personal factors}

The ICF categories linked to the items of eight PROMs $[36,45,51,59,64,68,70,76]$ were used from existing literature $[28,77,78]$. The mapping of $P F s$ to the PROMs is depicted in Table 4.

The PFs coping and reflecting about life in an optimistic way were covered most frequently (each by 14 PROMs), followed by resilience and self-efficacy (each by 12 PROMs). Compared to that, job satisfaction was not covered by any of the PROMs. The PF own attitudes was covered by six, involvement into disease management by five, sense of coherence by four and meaningful activities by two PROMs. Adaptation to changed living conditions, social appreciation and eating habits and weight concerns were covered once, each by the London Coping with Rheumatoid Arthritis Questionnaire (LCRAQ) [79].

The LCRAQ covered most (nine) PFs, followed by the General Self-Efficacy Scale (GSES) [48,49] which covered six PFs. The Arthritis Self-Efficacy Scale (ASES) [38], the Rheumatoid Arthritis Self-Efficacy Questionnaire (RASE) [67] and the Revised Ways of Coping Inventory (WOC-R) [74] captured five PFs each. Nineteen of the 42 explored 


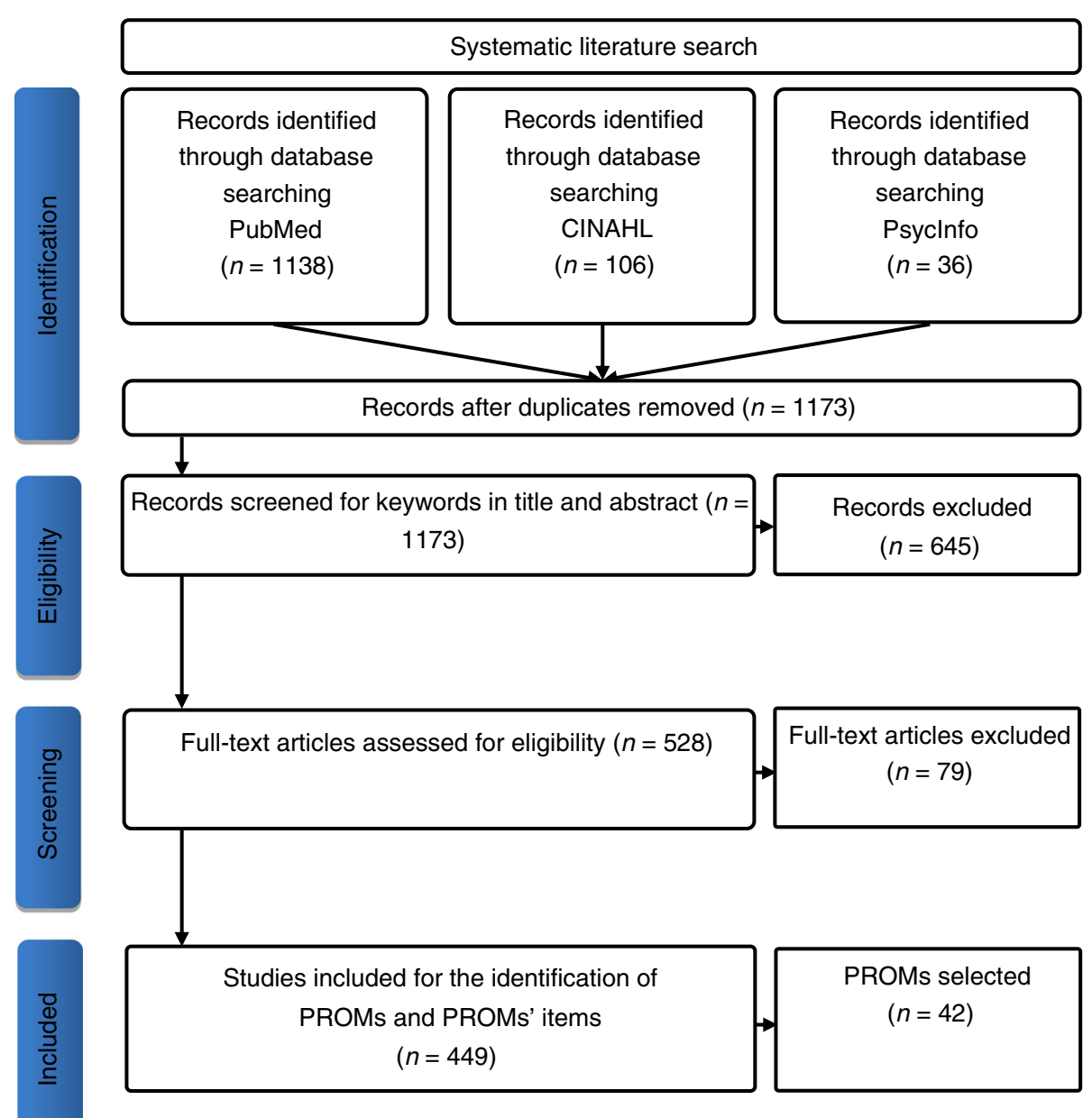

Figure 3 Flow diagram.

PROMs covered no $P F$, including the different versions of the Health Assessment Questionnaire (HAQ) except the 14. Activities of Daily Living Multidimensional HAQ (14 ADLMDHAQ) [51-53,61,75], as shown in Table 4.

\section{Discussion}

In the current study we identified 12 PFs being important in the life stories of people with RA and explored their coverage by 42 PROMs used in RA. The results of this study can support health professionals and researchers in their selection of which PROMs to use, when assessing the need for or evaluating the effect of non-pharmacological treatment in clinical practice or rehabilitation [80] targeting the identified $P F s$.

PFs which were found to be important to people with RA could get more emphasis in ICF-based health outcome research. For example, self-efficacy was found to facilitate the maintenance of physical activity [4] and to decrease fatigue [81], pain [82] and the development of cardiovascular risk $[83,84]$. Since cardiovascular diseases account for approximately $50 \%$ of mortality [85], the prevention of cardiovascular risk is an important target in the disease management of RA [86] including pharmacological and non-pharmacological methods [87]. Thus, health outcome research focusing on PFS with strong evidence for their health determining effect could be of great value to support individuals achieving their fullest functioning and health.

Due to unequal proportion of female and male participants, the identified gender differences of PFs need to be treated with caution. The findings could indicate a difference in the meaning of these PFS in the life stories between women and men with RA. Therefore, the selection of the outcomes and related PROMs should take into account potential gender differences to consider the preferences and values regarding PFs of women and men in the evaluation of health care interventions.

Even though, most of the explored PROMs were not designed to assess a range of $P F s$, one PROM was outstanding in its coverage of PFs: the LCRAQ which could be used to address most of the identified PFs. The GSES could be 
Table 3 Characteristics of the identified patient-reported outcome measures

\begin{tabular}{|c|c|c|}
\hline Abbreviations & Names of patient-reported outcome measures & Items \\
\hline AIMS2-SF & Arthritis Impact Measurement Scales Short Form [36] & 26 \\
\hline $\mathrm{APaQ}$ & Activity Participation Questionnaire [37] & 2 \\
\hline ASES & Arthritis Self-Efficacy Scale [38] & 20 \\
\hline B-WOC-R & Brief Revised Ways of coping inventory [39] & 18 \\
\hline BRAF MDQ & Bristol Arthritis Fatigue Multi-Dimensional Questionnaire [40] & 20 \\
\hline BRAF NRS & Bristol Arthritis Fatigue Numerical Rating Scale [40] & 3 \\
\hline CFS & Chalder Fatigue Scale [41] & 11 \\
\hline CIS 20R & Checklist Individual Strength [42] & 20 \\
\hline $\mathrm{CIS} 8 \mathrm{R}$ & Checklist Individual Strength [42] & 8 \\
\hline C-RAQ & Coping with Rheumatoid Arthritis Questionnaire [25] & 20 \\
\hline DRP & Disease Repercussion Profile [43] & 6 \\
\hline EC-17 & Effective Musculoskeletal Consumer Scale (Short Form) [44] & 17 \\
\hline EQ-5D & EuroQuoL Health questionnaire [45] & 5 \\
\hline FACIT-F & Functional Assessment Chronic Illness Therapy (Fatigue) [46] & 13 \\
\hline FSS & Fatigue Severity Scale [47] & 9 \\
\hline GSES & General Self-Efficacy Scale $[48,49]$ & 10 \\
\hline HADS & Hospital Anxiety and Depression Scale [50] & 14 \\
\hline $\mathrm{HAQ}$ & Health Assessment Questionnaire [51] & 20 \\
\hline HAQ-II & Health assessment questionnaire ii [52] & 10 \\
\hline HAQ-DI & Health Assessment Questionnaire Disability Index [53] & 20 \\
\hline JP SES & Joint Protection Self-efficacy Scale [54] & 10 \\
\hline LCRAQ & London Coping with Rheumatoid Arthritis Questionnaire [55] & 36 \\
\hline LOT-R & Life Orientation Test-Revised [56] & 8 \\
\hline MAF & Multi-dimensional Assessment of Fatigue [57] & 15 \\
\hline MFI & Multi-dimensional Fatigue Inventory [58] & 20 \\
\hline MHAQ & Modified Health Assessment Questionnaire [59] & 8 \\
\hline MHLC - C & Multidimensional Health Locus of Control C-Form [60] & 18 \\
\hline $\mathrm{PI}-\mathrm{HAQ}$ & Personal Impact Health Assessment Questionnaire [61] & 20 \\
\hline PRO-CLARA & Patient Reported Outcome - Clinical Arthritis Activity [62] & 21 \\
\hline RAID & Rheumatoid Arthritis Impact of Disease score [63] & 12 \\
\hline RAPID 3 & Routine Assessment of Patient Index Data [64] & 24 \\
\hline RAQoL & Rheumatoid Arthritis Quality of life [65] & 30 \\
\hline ROAD & Recent-Onset Arthritis Disability Index [66] & 12 \\
\hline RASE & Rheumatoid Arthritis Self-Efficacy Questionnaire [67] & 28 \\
\hline SACRAH & Score for Assessment \& Quantification of Chronic Rheumatoid Affections of the Hands [68] & 23 \\
\hline SF-36 & Short-Form Health Survey 36-item $[69,70]$ & 36 \\
\hline SOC-13 & Sense of Coherence scale-13 [71] & 13 \\
\hline SSQS \& SQT & Social Support Questionnaire Transactions \& Satisfaction with supportive transactions [72] & 46 \\
\hline SSS & MOS Social Support Survey [73] & 20 \\
\hline WOC-R & Revised Ways of Coping Inventory [74] & 50 \\
\hline 10 ADLMDHAQ & 10 Activities of Daily Living Multidimensional Health Assessment Questionnaire [75] & 10 \\
\hline 14 ADLMDHAQ & 14 Activities of Daily Living Multidimensional Health Assessment Questionnaire [75] & 14 \\
\hline
\end{tabular}


Table 4 Coverage of personal factors by patient-reported outcome measures

\begin{tabular}{|c|c|c|c|c|}
\hline \multirow[b]{2}{*}{ PROMs } & \multicolumn{4}{|c|}{ Important personal factors } \\
\hline & $\begin{array}{l}\text { Adaptation to changed } \\
\text { living conditions }\end{array}$ & Coping & $\begin{array}{l}\text { Eating habits \& weight } \\
\text { concerns }\end{array}$ & $\begin{array}{l}\text { Involvement into } \\
\text { disease management }\end{array}$ \\
\hline \multicolumn{5}{|l|}{ AIMS2-SF } \\
\hline \multicolumn{5}{|l|}{$\mathrm{APaQ}$} \\
\hline ASES & & + & & + \\
\hline B-WOC-R & & + & & \\
\hline \multicolumn{5}{|l|}{ BRAF MDQ } \\
\hline BRAF NRS & & + & & \\
\hline \multicolumn{5}{|l|}{ CFQ } \\
\hline \multicolumn{5}{|l|}{ CIS 20R } \\
\hline \multicolumn{5}{|l|}{ CIS $8 \mathrm{R}$} \\
\hline C-RAQ & & + & & \\
\hline \multicolumn{5}{|l|}{ DRP } \\
\hline EC-17 & & + & & + \\
\hline \multicolumn{5}{|l|}{ EQ-5D } \\
\hline FACIT-F & & + & & \\
\hline \multicolumn{5}{|l|}{ FSS } \\
\hline GSES & & + & & \\
\hline \multicolumn{5}{|l|}{ HADS } \\
\hline \multicolumn{5}{|l|}{ HAQ } \\
\hline \multicolumn{5}{|l|}{ HAQ-II } \\
\hline \multicolumn{5}{|l|}{ HAQ-DI } \\
\hline \multicolumn{5}{|l|}{ JP SES } \\
\hline LCRAQ & + & + & + & + \\
\hline \multicolumn{5}{|l|}{ LOT-R } \\
\hline \multicolumn{5}{|l|}{ MAF } \\
\hline \multicolumn{5}{|l|}{ MFI } \\
\hline \multicolumn{5}{|l|}{ MHAQ } \\
\hline MHLC-C & & + & & \\
\hline \multicolumn{5}{|l|}{ PI-HAQ } \\
\hline \multicolumn{5}{|l|}{ PRO-CLARA } \\
\hline RAID & & + & & + \\
\hline RAPID 3 & & + & & \\
\hline RASE & & + & & \\
\hline \multicolumn{5}{|l|}{ RAQoL } \\
\hline \multicolumn{5}{|l|}{ ROAD } \\
\hline \multicolumn{5}{|l|}{ SACRAH } \\
\hline SF-36 & & & & \\
\hline SOC-13 & & & & \\
\hline SSQT \& -S & & & & \\
\hline SSS & & & & \\
\hline WOC-R & & + & & + \\
\hline 10 ADLMDHAQ & & & & \\
\hline 14 ADLMDHAQ & & + & & \\
\hline
\end{tabular}


Table 4 Coverage of personal factors by patient-reported outcome measures (Continued)

\begin{tabular}{|c|c|c|c|c|}
\hline \multirow[b]{2}{*}{ PROMs } & \multicolumn{4}{|c|}{ Important personal factors } \\
\hline & Job satisfaction & $\begin{array}{l}\text { Meaningful activities for the } \\
\text { individual/the social context }\end{array}$ & Own attitudes & $\begin{array}{l}\text { Reflecting about one's life } \\
\text { in an optimistic way }\end{array}$ \\
\hline \multicolumn{5}{|l|}{ AIMS2-SF } \\
\hline \multicolumn{5}{|l|}{$\mathrm{APaQ}$} \\
\hline ASES & & & + & \\
\hline B-WOC-R & & & & + \\
\hline \multicolumn{5}{|c|}{ BRAF MDQ } \\
\hline \multicolumn{5}{|c|}{ BRAF NRS } \\
\hline \multicolumn{5}{|l|}{ CFQ } \\
\hline \multicolumn{5}{|l|}{ CIS 20R } \\
\hline \multicolumn{5}{|l|}{ CIS 8R } \\
\hline C-RAQ & & & & + \\
\hline DRP & & & & + \\
\hline EC-17 & & & & + \\
\hline \multicolumn{5}{|l|}{ EQ-5D } \\
\hline FACIT-F & & + & & + \\
\hline \multicolumn{5}{|l|}{ FSS } \\
\hline GSES & & & + & + \\
\hline HADS & & & & + \\
\hline \multicolumn{5}{|l|}{ HAQ } \\
\hline \multicolumn{5}{|l|}{ HAQ-II } \\
\hline \multicolumn{5}{|l|}{ HAQ-DI } \\
\hline \multicolumn{5}{|l|}{ JP SES } \\
\hline LCRAQ & & & + & + \\
\hline LOT-R & & & & + \\
\hline \multicolumn{5}{|l|}{ MAF } \\
\hline \multicolumn{5}{|l|}{ MFI } \\
\hline \multicolumn{5}{|l|}{ MHAQ } \\
\hline MHLC-C & & & + & + \\
\hline \multicolumn{5}{|l|}{ PI-HAQ } \\
\hline \multicolumn{5}{|c|}{ PRO-CLARA } \\
\hline \multicolumn{5}{|l|}{ RAID } \\
\hline \multicolumn{5}{|l|}{ RAPID 3} \\
\hline RASE & & & + & + \\
\hline RAQoL & & & & + \\
\hline \multicolumn{5}{|l|}{ ROAD } \\
\hline \multicolumn{5}{|l|}{ SACRAH } \\
\hline SF-36 & & & + & \\
\hline SOC-13 & & + & & + \\
\hline \multicolumn{5}{|c|}{ SSQT \& -S } \\
\hline SSS & & & & \\
\hline WOC-R & & & & + \\
\hline 10 ADLM & & & & \\
\hline 14 ADLM & & & & \\
\hline
\end{tabular}


Table 4 Coverage of personal factors by patient-reported outcome measures (Continued)

\begin{tabular}{|c|c|c|c|c|}
\hline \multirow[b]{2}{*}{ PROMs } & \multicolumn{4}{|c|}{ Important personal factors } \\
\hline & Resilience & Self-efficacy & Sense of coherence & Social appreciation \\
\hline \multicolumn{5}{|l|}{ AIMS2-SF } \\
\hline \multicolumn{5}{|l|}{$\mathrm{APaQ}$} \\
\hline ASES & & + & + & \\
\hline B-WOC-R & + & + & & \\
\hline \multicolumn{5}{|l|}{ BRAF MDQ } \\
\hline \multicolumn{5}{|l|}{ BRAF NRS } \\
\hline \multicolumn{5}{|l|}{ CFQ } \\
\hline \multicolumn{5}{|l|}{ CIS 20R } \\
\hline \multicolumn{5}{|l|}{ CIS 8R } \\
\hline C-RAQ & + & + & & \\
\hline \multicolumn{5}{|l|}{ DRP } \\
\hline EC-17 & & + & & \\
\hline \multicolumn{5}{|l|}{ EQ-5D } \\
\hline FACIT-F & + & & & \\
\hline \multicolumn{5}{|l|}{ FSS } \\
\hline GSES & + & + & + & \\
\hline HADS & + & & & \\
\hline \multicolumn{5}{|l|}{ HAQ } \\
\hline \multicolumn{5}{|l|}{ HAQ-II } \\
\hline \multicolumn{5}{|l|}{ HAQ-DI } \\
\hline JP SES & & + & & \\
\hline LCRAQ & + & + & & + \\
\hline LOT-R & + & & + & \\
\hline MAF & + & & & \\
\hline MFI & & + & & \\
\hline \multicolumn{5}{|l|}{ MHAQ } \\
\hline MHLC-C & & + & & \\
\hline \multicolumn{5}{|l|}{ PI-HAQ } \\
\hline \multicolumn{5}{|l|}{ PRO-CLARA } \\
\hline \multicolumn{5}{|l|}{ RAID } \\
\hline RAPID 3 & + & & & \\
\hline RASE & + & + & & \\
\hline RAQoL & & + & & \\
\hline \multicolumn{5}{|l|}{ ROAD } \\
\hline \multicolumn{5}{|l|}{ SACRAH } \\
\hline \multicolumn{5}{|l|}{ SF-36 } \\
\hline SOC-13 & & & + & \\
\hline \multicolumn{5}{|l|}{ SSQT \& -S } \\
\hline \multicolumn{5}{|l|}{ SSS } \\
\hline WOC-R & + & + & & \\
\hline \multicolumn{5}{|l|}{10 ADLMDHAQ } \\
\hline 14 ADLMDHAQ & & & & \\
\hline
\end{tabular}


employed to measure six PFs. Additionally, the ASES, the RASE and the WOC-R were found to assess five different $P F s$, respectively. While the PFs coping, reflecting about one's life in an optimistic way and sense of coherence could be assessed by all of these PROMs, adaptation to changed living conditions, eating habits and weight concerns, and social appreciation was found to be covered by the LCRAQ only. In addition, the PROMs which covered most of the PFs, could be used to measure the PFs own attitudes (except the WOC-R) and resilience (except the ASES). Consequently, one of these PROMs could be selected for the evaluation of health care interventions having regard to the different PFs important in the life stories of people with RA. However, for the use in clinical practice and research, other psychometric properties and applicability in different cultural contexts need to be considered.

Commonly used PROMs in clinically routine, e.g. the HAQ could be combined with others. Only the 14 ADLMDHAQ [75] covers PFs $(n=2)$, while the other versions of the HAQ do not cover any of the PFs. In addition, it would be interesting to develop RA specific PROMs that address adaptation to changed living conditions, social appreciation, eating habits and weight concerns, job satisfaction and meaningful activities, since these PFs have rarely been addressed in the PROMs. In the clinical routine and rehabilitation, health professionals such as nurses, occupational therapists or physiotherapists, may use other assessments and thus, could address PFs to complement and/or to conduce to success of pharmacological treatment for people with RA [26].

This research had some limitations. An inclusion of PROMs published in various languages could give valuable information about their potential utilization to assess $P F s$. Another study could include PFs important to patients of younger age to determine their coverage of PROMs, based on previous research [88]. In addition, further studies could focus on the perspectives of patients of different cultural backgrounds or specific person groups such as parents or patients with recent onset. The so called member checking method could have contributed to the credibility of the findings. In the current project we explored the content validity of PROMs, referring to their coverage of concepts which are relevant to the target population [89]. Despite determining PROMs' content validity, a critical appraisal of other measurement properties could have provided additional important information. However, we did not explore other psychometric properties of the selected PROMs since this was not the focus of our study. Additional studies are warranted to generalize the findings of the current project to other people with RA.

\section{Conclusion}

Taken together, the identified PFs are important in the life stories of people with RA and could be addressed in clinical practice and rehabilitation by different health professionals in order to support their patients' functioning and health. The LCRAQ, the GSES, the ASES, the RASE and the WOC-R could be used when assessing the need for or evaluating health care interventions targeting the identified PFs and thus contribute to an increasing benefit for people with RA. Furthermore the findings can be used for further development of existing PROMs and to guide their use in clinical practice, rehabilitation and research.

\begin{abstract}
Abbreviations
ASES: Arthritis self-efficacy scale; GSES: General self-efficacy scale; HAQ: Health assessment questionnaire; ICF: International classification of functioning, disability and health; LCRAQ: London coping with rheumatoid arthritis questionnaire; MDHAQ: Multidimensional health assessment questionnaire; PF (s): Personal factor (s); PROM (s): Patient-reported outcome measure (s); RA: Rheumatoid arthritis; RASE: The rheumatoid arthritis self-efficacy questionnaire; WOC-R: Revised ways of coping inventory.
\end{abstract}

\section{Competing interests}

The authors declare that they have no competing interests.

\section{Authors' contributions}

$M D, J S$, and TAS were involved into conception and design, the acquisition of data, the analysis and interpretation of data, wrote the draft manuscript, and gave final approval of the manuscript. RD assisted the data acquisition, analysis and interpretation, and the draft version, and finally gave advice on editing of manuscript. AK-W and VF-M gave substantial contributions to conception and design, supported the acquisition of the data, have been involved in revising the draft manuscript critically, and finally approved the manuscript considered for publication. MC, IK, MAS, MM and CB supported the analysis and interpretation of the data, contributed substantially to the draft manuscript and approved the final version. The authors have taken an active part in the study and take responsibility for its contents. The FWF did not have any influence on the manuscript. All authors read and approved the final manuscript.

\section{Acknowledgements}

We thank patients for their participation and the important contributions for this study. We thank authors for the provision of "unavailable" PROMs. Furthermore we thank Herta Resch for the interview transcription and Alexa Binder for extracting relevant information about PROMs in the respective literature. The current study, as a part of a larger project was funded by the Austrian Science Fund (FWF): [P21912-B09]. The FWF did not review the manuscript nor had any influence over the manuscript content

\section{Funding}

Partly funded by a restricted grant of the Austrian Science Fund (FWF): [P21912-B09].

\section{Data sharing statement}

Data from this study will be made available upon request to the corresponding author (TAS), in accordance with relevant guidelines from the funding agency and the ethical approval of the ethic committee of the Medical University of Vienna, Austria.

\section{Author details}

${ }^{1}$ Medical University of Vienna, Department of Internal Medicine III, Division of Rheumatology, Währinger Gürtel 18-20, 1090 Vienna, Austria. ${ }^{2}$ IMC University of Applied Sciences Krems, Department of Health Sciences, Occupational Therapy, Piaristengasse 1, 3500 Krems, Austria. ${ }^{3}$ Ludwig-Maximilians-University, Department of Medical Informatics, Biometry and Epidemiology, Research Unit for Bio Psychosocial Health, Marchioninistraße 17, 81377 Munich, Germany. ${ }^{4}$ Medical University of Vienna, Department of Physical Medicine and Rehabilitation, Währinger Gürtel 18-20, 1090 Vienna, Austria. ${ }^{5}$ Medical University of Vienna, Department of Internal Medicine III, Division of Diabetology, Währinger Gürtel 18-20, 1090 Vienna, Austria. ${ }^{6}$ Diakonhjemmet Hospital, National Advisory 
Unit on Rehabilitation in Rheumatology, Department of Rheumatology, Postbox 23 Vinderen, 0319 Oslo, Norway. " "Victor Babeş" University of Medicine and Pharmacy, Department of Rehabilitation, Physical Medicine and Rheumatology, Piata Eftimie Murgu 2, Timişoara 300041, Timis, Romania. ${ }^{8}$ Luleå University of Technology, Department of Health Sciences, SE-971 87, Luleå, Sweden. ${ }^{9}$ Sunderby Hospital, Department of Physiotherapy, SE-971 80, Luleå, Sweden. ${ }^{10}$ Karolinska Institutet, Department of Neurobiology, Care sciences and Society, Division of Physiotherapy, Alfred Nobels Allé 23, 14183 Huddinge, Stockholm Sweden. ${ }^{11}$ Fachhochschule Campus Wien, University of Applied Sciences, Department of Health, Favoritenstraße 226, 1100 Vienna, Austria.

Received: 11 April 2014 Accepted: 24 January 2015

Published online: 25 February 2015

\section{References}

1. WHO. The Burden of Musculoskeletal Conditions at the Start of the New Millenium, Technical Report Series,No.919. Geneva: World Health Organization; 2003.

2. Lesuis N, Befrits R, Nyberg F, van Vollenhoven RF. Gender and the treatment of immune-mediated chronic inflammatory diseases: rheumatoid arthritis, inflammatory bowel disease and psoriasis: an observational study. BMC Med. 2012;10:82.

3. Cutolo M, Kitas GD, van Riel PL. Burden of disease in treated rheumatoid arthritis patients: Going beyond the joint. Semin Arthritis Rheum. 2014;43:479-88.

4. Demmelmaier I, Bergman P, Nordgren B, Jensen I, Opava CH. Current and maintained health-enhancing physical activity in rheumatoid arthritis: a cross-sectional study. Arthritis Care Res (Hoboken). 2013;65:1166-76.

5. Dickens C, McGowan L, Clark-Carter D, Creed F. Depression in rheumatoid arthritis: A systematic review of the literature with meta-analysis. Psychosom Med. 2002;64:52-60.

6. WHO. ICF - International Classification of Functioning, Disability and Health Geneva: World Health Organization; 2001.

7. WHO. How to use the ICF: A practical manual for using the International Classification of Functioning, Disability and Health (ICF). Exposure draft for comment. Geneva: World Health Organization; 2013.

8. Grotkamp S, Cibis W, Nuchtern E, von Mittelstaedt G, Seger W. Personal Factors in the International Classification of Functioning, Disability and Health: Prospective Evidence. Aust J Rehab Couns. 2012;18:1-24.

9. Geyh S, Peter C, Muller R, Bickenbach JE, Kostanjsek N, Ustun BT, et al. The Personal Factors of the International Classification of Functioning, Disability and Health in the literature - a systematic review and content analysis. Disabil Rehabil. 2011;33:1089-102.

10. $\mathrm{Ng} \mathrm{L}$, Khan F. Identification of personal factors in motor neurone disease: a pilot study. Rehabil Res Pract. 2011;2011:7.

11. Stucki G, Cieza A, Geyh S, Battistella L, Lloyd J, Symmons D, et al. ICF Core Sets for rheumatoid arthritis. J Rehabil Med. 2004;(44 Suppl):87-93.

12. Gebhardt C, Kirchberger I, Stucki G, Cieza A. Validation of the comprehensive ICF Core Set for rheumatoid arthritis: The perspective of physicians. J Rehabil Med. 2010;42:780-8.

13. Kirchberger I, Cieza A, Stucki G. Validation of the Comprehensive ICF Core Set for rheumatoid arthritis: The perspective of psychologists. Psychol Health. 2008:23:639-59.

14. Coenen M, Cieza A, Stamm TA, Amann E, Kollerits B, Stucki G. Validation of the International Classification of Functioning, Disability and Health (ICF) Core Set for rheumatoid arthritis from the patient perspective using focus groups. Arthritis Res Ther. 2006;8:R84.

15. Stamm TA, Cieza A, Coenen M, Machold KP, Nell VP, Smolen JS, et al. Validating the International Classification of Functioning, Disability and Health Comprehensive Core Set for Rheumatoid Arthritis from the patient perspective: A qualitative study. Arthritis Rheum. 2005;53:431-9.

16. Ahlstrand I, Bjork M, Thyberg I, Borsbo B, Falkmer T. Pain and daily activities in rheumatoid arthritis. Disabil Rehabil. 2012;34:1245-53.

17. Primdahl J, Wagner L, Horslev-Petersen K. Being an outpatient with rheumatoid arthritis-a focus group study on patients' self-efficacy and experiences from participation in a short course and one of three different outpatient settings. Scand J Caring Sci. 2011;25:394-403.

18. Kuspinar A, Mayo NE. Do generic utility measures capture what is important to the quality of life of people with multiple sclerosis? Health Qual Life Outcomes. 2013;11:71.

19. Stamm TA, Nell V, Mathis M, Coenen M, Aletaha D, Cieza A, et al. Concepts important to patients with psoriatic arthritis are not adequately covered by standard measures of functioning Arthritis Rheum. 2007:57:487-94

20. Stamm TA, Bauernfeind B, Coenen M, Feierl E, Mathis M, Stucki G, et al. Concepts important to persons with systemic lupus erythematosus and their coverage by standard measures of disease activity and health status. Arthritis Rheum. 2007;57:1287-95.

21. Lazarus RS, Folkman S. Stress, Appraisal, and Coping. New York: Springer; 1984

22. Steptoe A, Dockray S, Wardle J. Positive affect and psychobiological processes relevant to health. J Pers. 2009;77:1747-76.

23. Meesters J, Verhoef J, Tijhuis G, Vliet Vlieland T. Functional disability in patients with rheumatoid arthritis admitted for multidisciplinary rehabilitation from 1992 to 2009. Rheumatology (Oxford). 2013;52:1879-83.

24. Woolf AD, Erwin J, March $L$. The need to address the burden of musculoskeletal conditions. Best Pract Res Clin Rheumatol. 2012;26:183-224.

25. Englbrecht M, Gossec L, DeLongis A, Scholte-Voshaar M, Sokka T, Kvien TK, et al. The impact of coping strategies on mental and physical well-being in patients with rheumatoid arthritis. Semin Arthritis Rheum. 2012;41:545-55.

26. Zwikker $\mathrm{HE}$, van den Ende $\mathrm{CH}$, van Lankveld WG, den Broeder $\mathrm{AA}$, van den Hoogen $\mathrm{FH}$, van de Mosselaar B, et al. Effectiveness of a group-based intervention to change medication beliefs and improve medication adherence in patients with rheumatoid arthritis: a randomized controlled trial. Patient Educ Couns. 2014;94:356-61.

27. Dür M, Steiner G, Fialka-Moser V, Kautzky-Willer A, Dejaco C, Prodinger B, et al. Development of a new occupational balance-questionnaire: incorporating the perspectives of patients and healthy people in the design of a self-reported occupational balance outcome instrument. Health Qual Life Outcomes. 2014;12:45.

28. Dür M, Sadlonova M, Haider S, Binder A, Stoffer M, Coenen M, et al. Health determining concepts important to people with Crohn's disease and their coverage by patient-reported outcomes of health and wellbeing. J Crohns Colitis. 2014:8:45-55

29. Stamm TA, Lovelock L, Stew G, Nell V, Smolen J, Machold K, et al. I have a disease but I am not ill: A narrative study of occupational balance in people with rheumatoid arthritis. OTJR. 2009;29:32-9.

30. Stamm T, Lovelock L, Stew G, Nell V, Smolen J, Jonsson H, et al. I have mastered the challenge of living with a chronic disease: Life stories of people with rheumatoid arthritis. Qual Health Res. 2008;18:658-69.

31. Arnett FC, Edworthy SM, Bloch DA, McShane DJ, Fries JF, Cooper NS, et al. The American Rheumatism Association 1987 revised criteria for the classification of rheumatoid arthritis. Arthritis Rheum. 1988;31:315-24.

32. Jones K. The turn to a narrative knowing of persons: One method explored. Nurs Time Res. 2002:1:1-11.

33. Wengraf T. Qualitative Research Interviewing: Biographic Narratives and Semi-Structured Methods. London: Sage Publications; 2001.

34. Rosenthal G. Reconstruction of Life Stories. Principles of Selection in Generating Stories of Narrative Biographical Interviews. In: Josselson R, Lieblich A, editors. The Narrative Study of Lives. Thousand Oaks: Sage; 1993. p. 59-91.

35. Cieza A, Geyh S, Chatterji S, Kostanjsek N, Ustun B, Stucki G. ICF linking rules: an update based on lessons learned. J Rehabil Med. 2005:37:212-8.

36. Meenan RF, Mason JH, Anderson JJ, Guccione AA, Kazis LE. AIMS2. The content and properties of a revised and expanded Arthritis Impact Measurement Scales Health Status Questionnaire. Arthritis Rheum. 1992;35:1-10.

37. Li T, Wells G, Westhovens R, Tugwell P. Validation of a simple activity participation measure for rheumatoid arthritis clinical trials. Rheumatology (Oxford). 2009;48:170-5

38. Lorig K, Chastain RL, Ung E, Shoor S, Holman HR. Development and evaluation of a scale to measure perceived self-efficacy in people with arthritis. Arthritis Rheum. 1989:32:37-44.

39. Newth S, Delongis A. Individual differences, mood, and coping with chronic pain in rheumatoid arthritis: A daily process analysis. Psychol Health. 2004;19:283-305.

40. Nicklin J, Cramp F, Kirwan J, Urban M, Hewlett S. Collaboration with patients in the design of patient-reported outcome measures: capturing the experience of fatigue in rheumatoid arthritis. Arthritis Care Res (Hoboken). 2010;62:1552-8.

41. Chalder T, Berelowitz G, Pawlikowska T, Watts L, Wessely S, Wright D, et al. Development of a fatigue scale. J Psychosom Res. 1993;37:147-53.

42. Vercoulen JHMM, Swanink CMA, Fennis JFM, Galama JMD, Vandermee JWM, Bleijenberg G. Dimensional Assessment of Chronic Fatigue Syndrome. J Psychosom Res. 1994;38:383-92.

43. Carr A. A Patient-centred Approach to Evaluation and Treatment in Rheumatoid Arthritis: the Development of a Clinical Tool to Measure Patient-perceived Handicap. Br J Rheumatol. 1996;35:921-32. 
44. Kristjansson E, Tugwell PS, Wilson AJ, Brooks PM, Driedger SM, Gallois C, et al. Development of the effective musculoskeletal consumer scale. J Rheumatol. 2007:34:1392-400

45. Rabin R, de Charro F. EQ-5D: a measure of health status from the EuroQol Group. Ann Med. 2001;33:337-43.

46. Yellen SB, Cella DF, Webster K, Blendowski C, Kaplan E. Measuring fatigue and other anemia-related symptoms with the Functional Assessment of Cancer Therapy (FACT) measurement system. J Pain Symptom Manage. 1997;13:63-74.

47. Krupp LB, LaRocca NG, Muir-Nash J, Steinberg AD. The fatigue severity scale. Application to patients with multiple sclerosis and systemic lupus erythematosus. Arch Neurol. 1989;46:1121-3.

48. Jerusalem M, Schwarzer R. Self-efficacy as a resource factor in stress appraisal processes. In: Schwarzer R, editor. Self-Efficacy: Thought Control of Action. Washington DC: Hemisphere; 1992.

49. Schwarzer R. Measurement of Perceived Self-Efficacy: Psychometric Scales for Cross-Cultural Research. Berlin: Freie Universität Berlin, Institut für Psychologie; 1993.

50. Zigmond AS, Snaith RP. The hospital anxiety and depression scale. Acta Psychiatr Scand. 1983;67:361-70.

51. Fries JF, Spitz P, Kraines RG, Holman HR. Measurement of patient outcome in arthritis. Arthritis Rheum. 1980;23:137-45.

52. Wolfe F, Michaud K, Pincus T. Development and validation of the health assessment questionnaire II: A revised version of the health assessment questionnaire. Arthritis Rheum. 2004;50:3296-305.

53. Fries JF, Spitz PW, Young DY. The dimensions of health outcomes: The health assessment questionnaire, disability and pain scales. J Rheumatol. 1982;9:789-93.

54. Niedermann K, Forster A, Ciurea A, Hammond A, Uebelhart D, de Bie R. Development and psychometric properties of a joint protection self-efficacy scale. Scand J Occup Ther. 2011;18:143-52.

55. Newman S, Fitzpatrick R, Lamb R, Shipley M. Patterns of Coping in Rheumatoid Arthritis. Psychol Health. 1990;4:187-200.

56. Scheier MF, Carver CS. Optimism, coping, and health: assessment and implications of generalized outcome expectancies. Health Psychol. 1985:4:219-47.

57. Tack B. Dimensions and correlates of fatigue in older adults with rheumatoid arthritis. San Francisco: University of California; 1991.

58. Smets EM, Garssen B, Bonke B, De Haes JC. The Multidimensional Fatigue Inventory (MFI) psychometric qualities of an instrument to assess fatigue. J Psychosom Res. 1995;39:315-25

59. Pincus T, Summey JA, Soraci Jr SA, Wallston KA, Hummon NP. Assessment of patient satisfaction in activities of daily living using a modified Stanford Health Assessment Questionnaire. Arthritis Rheum. 1983;26:1346-53.

60. Wallston KA, Stein MJ, Smith CA. Form C of the MHLC scales: a conditionspecific measure of locus of control. J Pers Assess. 1994;63:534-53.

61. Hewlett S, Smith AP, Kirwan JR. Measuring the meaning of disability in rheumatoid arthritis: the Personal Impact Health Assessment Questionnaire (PI HAQ). Ann Rheum Dis. 2002;61:986-93.

62. Salaffi F, Migliore A, Scarpellini M, Corsaro SM, Lagana B, Mozzani F, et al. Psychometric properties of an index of three patient reported outcome (PRO) measures, termed the CLinical ARthritis Activity (PRO-CLARA) in patients with rheumatoid arthritis. The NEW INDICES study. Clin Exp Rheumatol. 2010;28:186-200.

63. Gossec L, Dougados M, Rincheval N, Balanescu A, Boumpas DT, Canadelo S, et al. Elaboration of the preliminary Rheumatoid Arthritis Impact of Disease (RAID) score: a EULAR initiative. Ann Rheum Dis. 2009;68:1680-5.

64. Pincus T, Swearingen CJ, Bergman M, Yazici Y. RAPID3 (Routine Assessment of Patient Index Data 3), a rheumatoid arthritis index without formal joint counts for routine care: proposed severity categories compared to disease activity score and clinical disease activity index categories. J Rheumatol. 2008;35:2136-47.

65. Whalley D, McKenna SP, de Jong Z, van der Heijde D. Quality of life in rheumatoid arthritis. Br J Rheumatol. 1997;36:884-8.

66. Salaffi F, Bazzichi L, Stancati A, Neri R, Cazzato M, Consensi A, et al. Development of a functional disability measurement tool to assess early arthritis: the Recent-Onset Arthritis Disability (ROAD) questionnaire. Clin Exp Rheumatol. 2005;23:628-36.

67. Hewlett S, Cockshott Z, Kirwan J, Barrett J, Stamp J, Haslock I. Developmen and validation of a self-efficacy scale for use in British patients with rheumatoid arthritis (RASE). Rheumatology (Oxford). 2001;40:1221-30.

68. Leeb BF, Sautner J, Andel I, Rintelen B. SACRAH: a score for assessment and quantification of chronic rheumatic affections of the hands. Rheumatology (Oxford). 2003;42:1173-8.
69. Ware JE. How to Score the Revised MOS Short-Form Health Scale (SF-36 ${ }^{\circledR}$ ). Boston, MA: The Health Institute, New England Medical Center Hospitals; 1988.

70. Ware Jr JE, Sherbourne CD. The MOS 36-item short-form health survey (SF-36). I. Conceptual framework and item selection. Med Care. 1992:30:473-83.

71. Antonovsky A. The structure and properties of the sense of coherence scale. Soc Sci Med. 1993;36:725-33.

72. Suurmeijer TP, Doeglas DM, Briancon S, Krijnen WP, Krol B, Sanderman R, et al. The measurement of social support in the 'European Research on Incapacitating Diseases and Social Support': the development of the Social Support Questionnaire for Transactions (SSQT). Soc Sci Med. 1995;40:1221-9.

73. Sherbourne CD, Stewart AL. The MOS social support survey. Soc Sci Med. 1991;32:705-14.

74. Folkman S, Lazarus RS. If it changes it must be a process: Study of emotion and coping during three stages of a college examination. J Pers Soc Psychol. 1985:48:150-70.

75. Pincus T, Swearingen C, Wolfe F. Toward a multidimensional Health Assessment Questionnaire (MDHAQ): assessment of advanced activities of daily living and psychological status in the patient-friendly health assessment questionnaire format. Arthritis Rheum. 1999;42:2220-30.

76. Sautner J, Andel I, Rintelen B, Leeb BF. Development of the M-SACRAH, a modified, shortened version of SACRAH (Score for the Assessment and Quantification of Chronic Rheumatoid Affections of the Hands). Rheumatology (Oxford). 2004;43:1409-13.

77. Stamm T, Geyh S, Cieza A, Machold K, Kollerits B, Kloppenburg M, et al. Measuring functioning in patients with hand osteoarthritis-content comparison of questionnaires based on the International Classification of Functioning, Disability and Health (ICF). Rheumatology (Oxford). 2006;45:1534-41.

78. Cieza A, Stucki G. Content comparison of health-related quality of life (HRQOL) instruments based on the international classification of functioning, disability and health (ICF). Qual Life Res. 2005;14:1225-37.

79. Folkman S, Lazarus RS. An analysis of coping in a middle-aged community sample. J Health Soc Behav. 1980;21:219-39.

80. WHO. Global Programme on Health Promotion Effectiveness (GPHPE). Accessed on 15.2.2014 under www.who.int/healthpromotion/areas/gphpe/en/.

81. Brekke M, Hjortdahl P, Kvien TK. Changes in self-efficacy and health status over 5 years: A longitudinal observational study of 306 patients with rheumatoid arthritis. Arthritis Rheum. 2003;49:342-8.

82. van Hoogmoed D, Fransen J, Bleijenberg G, van Riel P. Physical and psychosocial correlates of severe fatigue in rheumatoid arthritis. Rheumatology (Oxford). 2010;49:1294-302.

83. Bartoloni E, Alunno A, Bistoni O, Gerli R. Cardiovascular risk in rheumatoid arthritis and systemic autoimmune rheumatic disorders: A suggested model of preventive strategy. Clin Rev Allergy Immunol. 2013;44:14-22.

84. Hurkmans EJ, van den Berg MH, Ronday KH, Peeters AJ, le Cessie S, Vlieland TP. Maintenance of physical activity after Internet-based physical activity interventions in patients with rheumatoid arthritis. Rheumatology (Oxford). 2010;49:167-72.

85. Avina-Zubieta JA, Thomas J, Sadatsafavi M, Lehman AJ, Lacaille D. Risk of incident cardiovascular events in patients with rheumatoid arthritis: A meta-analysis of observational studies. Ann Rheum Dis. 2012;71:1524-9.

86. Scrivo R, Vasile M, Muller-Ladner U, Neumann E, Valesini G. Rheumatic Diseases and Obesity: Adipocytokines as Potential Comorbidity Biomarkers for Cardiovascular Diseases. Mediators Inflamm. 2013;2013:808125.

87. Combe B, Landewe R, Lukas C, Bolosiu HD, Breedveld F, Dougados M, et al EULAR recommendations for the management of early arthritis: report of a task force of the European Standing Committee for International Clinical Studies Including Therapeutics (ESCISIT). Ann Rheum Dis. 2007:66:34-45.

88. Petersson C, Simeonsson RJ, Enskar K, Huus K. Comparing children's selfreport instruments for health-related quality of life using the International Classification of Functioning, Disability and Health for Children and Youth (ICF-CY). Health Qual Life Outcomes. 2013;11:75.

89. Mokkink LB, Terwee CB, Patrick DL, Alonso J, Stratford PW, Knol DL, et al. The COSMIN study reached international consensus on taxonomy, terminology, and definitions of measurement properties for health-related patient-reported outcomes. J Clin Epidemiol. 2010;63:737-45. 